\title{
Size Control of the MOF NU-1000 Through Manipulation of the Modulator/Linker Competition
}

\author{
Thomas E. Webber, ${ }^{1}$ Sai Puneet Desai, ${ }^{1}$ Rebecca L. Combs, ${ }^{1}$ Spencer Bingham, ${ }^{2}$ Connie C. Lu, ${ }^{1}$ R. Lee Penn ${ }^{1}$ \\ ${ }^{1}$ Department of Chemistry, University of Minnesota, Minneapolis, Minnesota 55455-0431, United States \\ ${ }^{2}$ Department of Chemistry, Carthage College, Kenosha, Wisconsin 53140, United States
}

\section{Supporting Information}




\begin{tabular}{|l|c|c|}
\hline & Table of Contents & Page \# \\
\hline S1 & Experimental/Methods & $3-4$ \\
\hline S2 & Particle Lengths, Widths, and Aspect Ratios & 4 \\
\hline S3 & Pore Size Distribution & 5 \\
\hline S4 & FTIR Spectroscopy & 6 \\
\hline S5 & 1H NMR Spectroscopy & $7-8$ \\
\hline S6 & Powder X-ray Diffraction & $8-9$ \\
\hline S7 & Dicobalt Complex Immobilization & 9 \\
\hline
\end{tabular}




\section{Experimental}

Materials: 1,3,6,8-tetrakis(p-benzoic acid)pyrene (synthesized by Rebecca Combs in the Penn group at the University of Minnesota), zirconyl chloride octahydrate (Sigma-Aldrich, 98\%), benzoic acid (Sigma-Aldrich, $\geq 99.5 \%$ ), biphenyl-4-carboxylic acid (Alfa Aesar, 98\%), N,N-dimethylformamide (Fisher Chemical, 99.9\%), sodium hydroxide (Ridel-de Haën, 99\%), acetone (Fisher Chemical, 99.7\%)

Synthesis of NU-1000: $\mathrm{ZrOCl}_{2} \bullet 8 \mathrm{H}_{2} \mathrm{O}$ is dissolved in $8 \mathrm{~mL} \mathrm{~N}, \mathrm{~N}$-dimethylformamide (DMF) with sonication before heating to $80^{\circ} \mathrm{C}$ for 1 hour on a hot plate equipped with an aluminum heating block and an IKA ETS-D5 Programmable Temperature Probe. Meanwhile, 1,3,6,8-tetrakis(p-benzoic acid)pyrene ( $\mathrm{H}_{4}$ TBAPy) is dissolved separately in $3 \mathrm{~mL} \mathrm{DMF}$ with sonication before adding $36 \mu \mathrm{L} 1 \mathrm{M}$ $\mathrm{NaOH}(a q)$. The $\mathrm{H}_{4}$ TBAPy solution undergoes additional sonication immediately prior to mixing with the node solution to ensure a consistent transfer, as some precipitation with the addition of $\mathrm{NaOH}$ occurs. After mixing the node and $\mathrm{H}_{4}$ TBAPy solutions, the resulting mixture is heated at $100{ }^{\circ} \mathrm{C}$ for 24 hours. The final mixture containing the precipitated NU-1000 is transferred to a centrifuge tube and centrifuged at 7,500 rpm for $5 \mathrm{~min}$ (up to 9,000 rpm for $15 \mathrm{~min}$ if necessary). The supernatant is decanted and replaced with $6 \mathrm{~mL}$ fresh DMF for subsequent centrifugation to separate particles from the washing solvent. The washing is performed 3 times. DMF $(12 \mathrm{~mL})$ is used to quantitatively transfer the NU-1000 back into a vial before adding $0.5 \mathrm{~mL} 8 \mathrm{M} \mathrm{HCl}$ and heating for at least 16 hours to release the remaining BPCA. The $\mathrm{NU}-1000$ is then washed 3 more times with $6 \mathrm{~mL}$ fresh DMF followed by 3 washes with $6 \mathrm{~mL}$ acetone. Finally, the NU-1000 is dried and activated in a vacuum oven at $120^{\circ} \mathrm{C}$ for 12 hours.

Synthesis of (pystren)CoCo@NU-1000: The metalation of NU-1000 follows reported

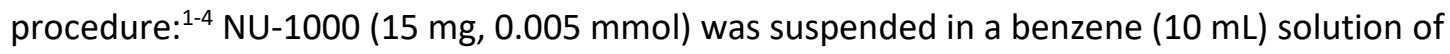
(pystren)CoCoOPh (8 mg, $0.014 \mathrm{mmol}$ ). The heterogeneous mixture was stirred at room temperature for $15 \mathrm{~h}$ and filtered through a fine porosity frit. The resulting solids were washed with copious amounts of benzene $(\sim 10 \mathrm{~mL})$ and hexane $(\sim 10 \mathrm{~mL})$. The solids were soaked overnight in $10 \mathrm{~mL}$ benzene and washed with fresh benzene $(4 \times 1 \mathrm{~mL})$ and pentane $(5 \times 1 \mathrm{~mL})$. The overnight soaking and rinsing procedure was repeated once more. Finally, the solids were dried under dynamic vacuum ( $<100 \mathrm{mTorr})$ for 5 h. Yield: $18 \mathrm{mg}(99 \%)$.

\section{Instrumentation and Characterization}

Bright field transmission electron microscopy was performed using a FEI Tecnai T12 operating at an accelerating voltage of $120 \mathrm{kV}$.

Scanning transmission electron microscopy-energy dispersive $\mathrm{X}$-ray spectroscopy (STEM-EDS) was performed using a FEI Tecnai G2 field-emission S/TEM operating at an accelerating voltage of $80 \mathrm{kV}$. High-angle annular dark field (HAADF) images were collected on an E. A. Fischione annular detector using an inner collection semiangle of $21.7 \mathrm{mrad}$. Energy-dispersive X-ray spectroscopy (EDS) spectra were obtained using the ChemiSTEM EDX spectrometer.

X-ray diffraction was performed using a PANalytical X'Pert Pro MPD diffractometer (XRD)

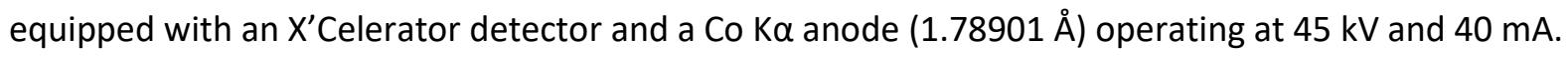


${ }^{1} \mathrm{H}$ NMR spectra were collected using a Bruker Avance III $400 \mathrm{MHz}$ spectrometer. Chemical shifts are reported with respect to the residual protio-solvent impurity for $1 \mathrm{H}(\mathrm{p}, 2.50 \mathrm{ppm}$ for $\left.\left(\mathrm{CHD}_{2}\right)\left(\mathrm{CD}_{3}\right) \mathrm{SO}\right)$.

\section{Particle Lengths, Widths, and Aspect Ratios}

Table S1. Particle length, width, and aspect ratio of the samples synthesized under a variety of synthetic conditions. ${ }^{\ddagger}$ No value given because individual particles could not be discerned from TEM images.

\begin{tabular}{|c|c|c|c|}
\hline \multirow{2}{*}{ Sample ID } & \multicolumn{3}{|c|}{ Particle Size } \\
\cline { 2 - 4 } & Length & Width & Aspect ratio \\
\hline R1 & $2.0 \pm 0.2 \mu \mathrm{m}$ & $0.90 \pm 0.1 \mu \mathrm{m}$ & 2.3 \\
\hline R2 & $4.7 \pm 0.5 \mu \mathrm{m}$ & $2.2 \pm 0.2 \mu \mathrm{m}$ & 2.1 \\
\hline R3 & $3.1 \pm 0.4 \mu \mathrm{m}$ & $1.4 \pm 0.2 \mu \mathrm{m}$ & 2.2 \\
\hline R4 & $1.6 \pm 0.4 \mu \mathrm{m}$ & $0.7 \pm 0.2 \mu \mathrm{m}$ & 2.3 \\
\hline REF $^{\Delta}$ & $2.9 \pm 0.8 \mu \mathrm{m}$ & $1.3 \pm 0.2 \mu \mathrm{m}$ & 2.2 \\
\hline $\mathbf{1}$ & $6.3 \pm 0.6 \mu \mathrm{m}$ & $1.7 \pm 0.1 \mu \mathrm{m}$ & 3.6 \\
\hline $\mathbf{2}$ & $3.2 \pm 0.3 \mu \mathrm{m}$ & $1.1 \pm 0.1 \mu \mathrm{m}$ & 2.8 \\
\hline $\mathbf{3}$ & $770 \pm 70 \mathrm{~nm}$ & $160 \pm 40 \mathrm{~nm}$ & 2.0 \\
\hline $\mathbf{4}$ & $-\ddagger$ & $--^{\ddagger}$ & $-{ }^{\ddagger}$ \\
\hline $\mathbf{5}$ & $300 \pm 30 \mathrm{~nm}$ & $160 \pm 20 \mathrm{~nm}$ & 1.9 \\
\hline $\mathbf{6}$ & $6.6 \pm 0.9 \mu \mathrm{m}$ & $2.7 \pm 0.3 \mu \mathrm{m}$ & 2.4 \\
\hline $\mathbf{7}$ & $2.7 \pm 0.1 \mu \mathrm{m}$ & $1.1 \pm 0.1 \mu \mathrm{m}$ & 2.4 \\
\hline $\mathbf{8}$ & $1.1 \pm 0.1 \mu \mathrm{m}$ & $0.5 \pm 0.1 \mu \mathrm{m}$ & 2.1 \\
\hline $\mathbf{9}$ & $420 \pm 30 \mathrm{~nm}$ & $190 \pm 10 \mathrm{~nm}$ & 2.2 \\
\hline $\mathbf{1 0}$ & $7.9 \pm 1.5 \mu \mathrm{m}$ & $3.3 \pm 0.5 \mu \mathrm{m}$ & 2.4 \\
\hline $\mathbf{1 1}$ & $9.3 \pm 2.1 \mu \mathrm{m}$ & $4.1 \pm 1.0 \mu \mathrm{m}$ & 2.4 \\
\hline $\mathbf{1 2}$ & $4.7 \pm 0.5 \mu \mathrm{m}$ & $2.1 \pm 0.2 \mu \mathrm{m}$ & 2.2 \\
\hline
\end{tabular}


Pore Size Distribution
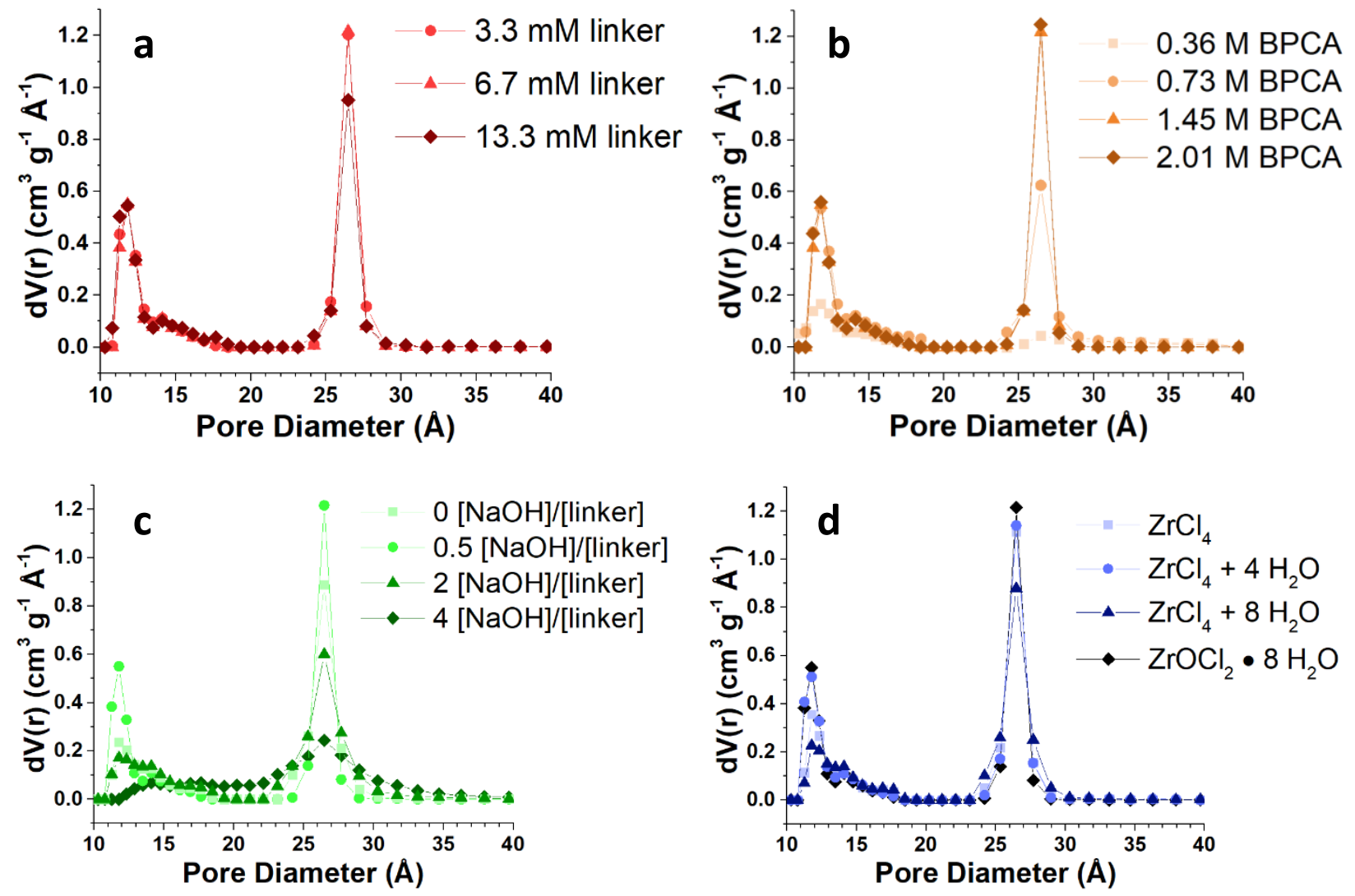

Figure S1. Pore size distributions for a) samples 2, R1, and 3, b) samples 4, 5, R1, and 6, c) samples 7, R1, 8, and 9, and d) samples 10-12 and R1. 


\section{FTIR Spectroscopy}

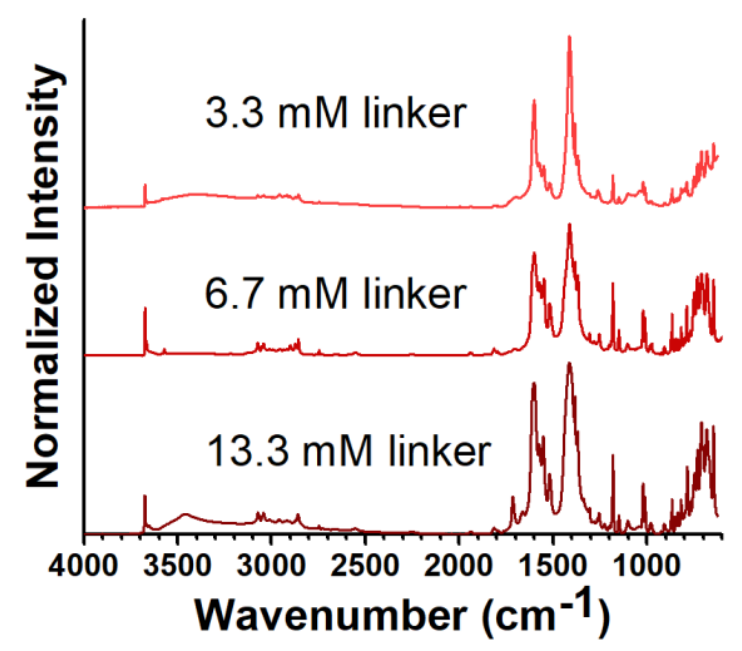

Figure S2. FTIR spectra for NU-1000 synthesized with varying concentration of linker.
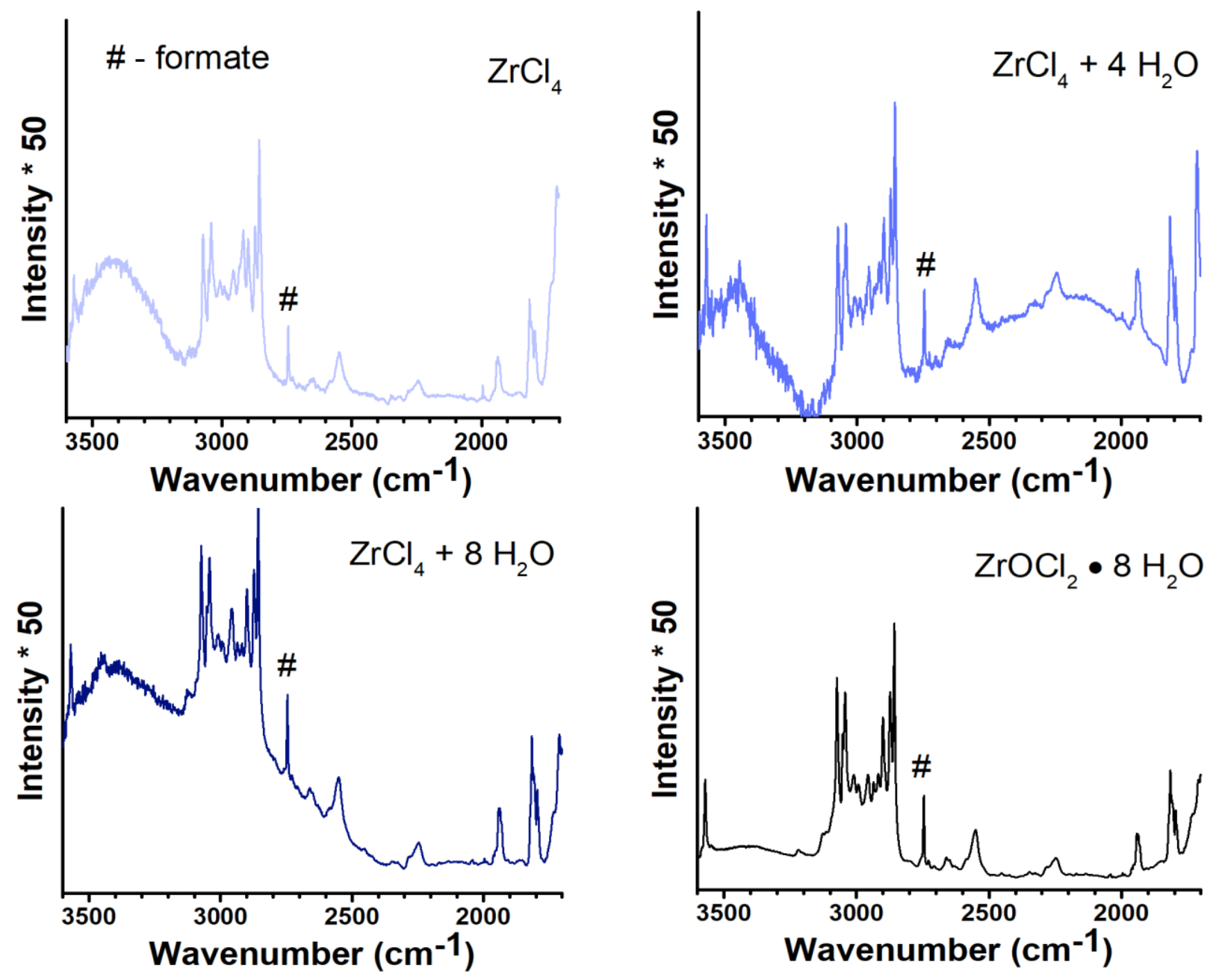

Figure S3. The same FTIR spectra for NU-1000 synthesized with varying Zr precursor and water concentration as Figure $6 \mathrm{~h}$. The spectra have been expanded in both $\mathrm{x}$ and $\mathrm{y}$ directions for clarity. The peak from formate is denoted with \#. 


\section{${ }^{1} \mathrm{H}$ NMR Spectroscopy}
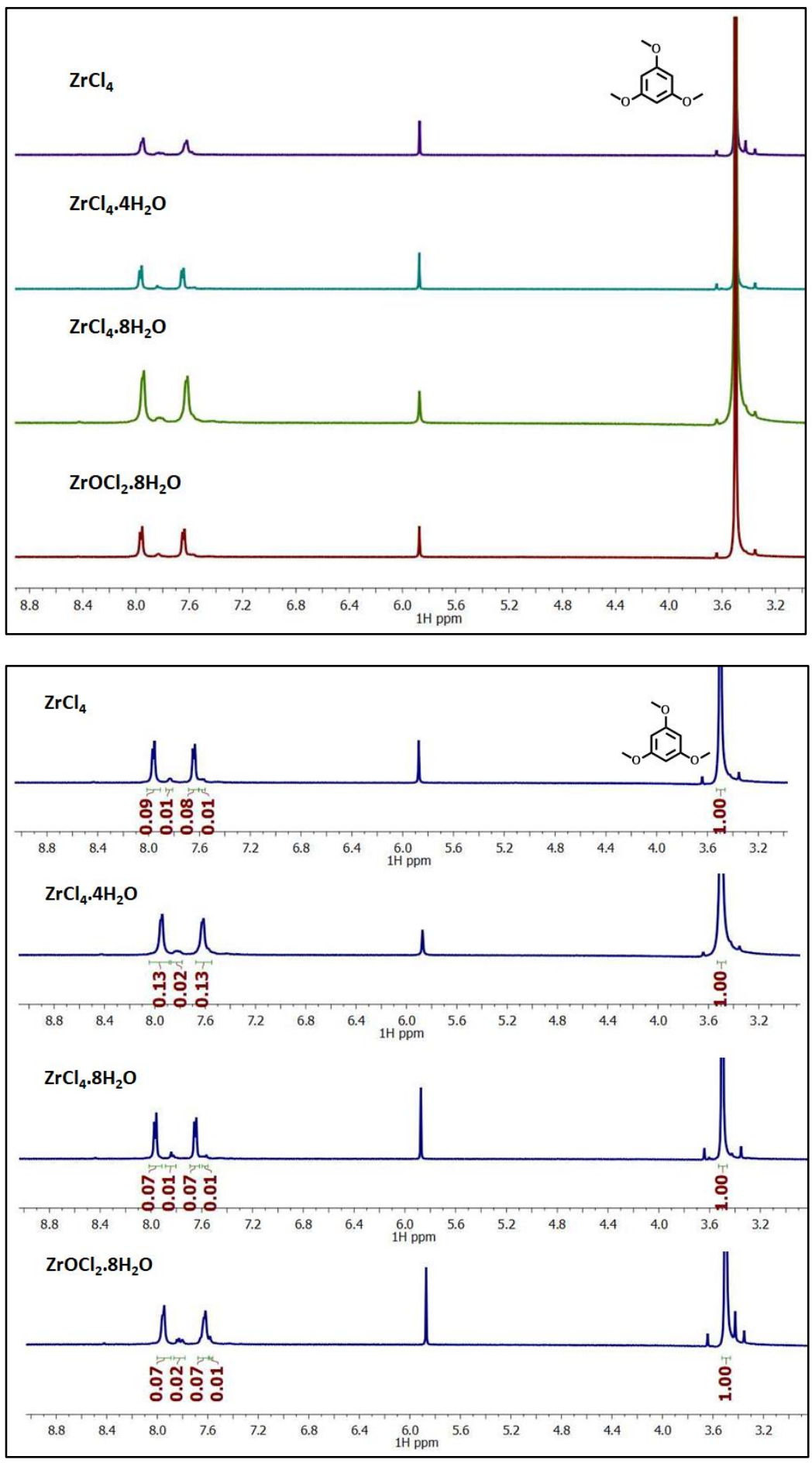

Figure S4. ${ }^{1} \mathrm{H}$ NMR spectra of NU-1000 synthesized with different water concentrations. Top: Peak intensities are normalized to the trimethoxybenzene peak at $3.5 \mathrm{ppm}$ to visually show difference in linker concentrations from the peaks between 7.6 and $8.0 \mathrm{ppm}$. Bottom: Same spectra showing the integrations normalized to the same trimethoxybenzene peak. 

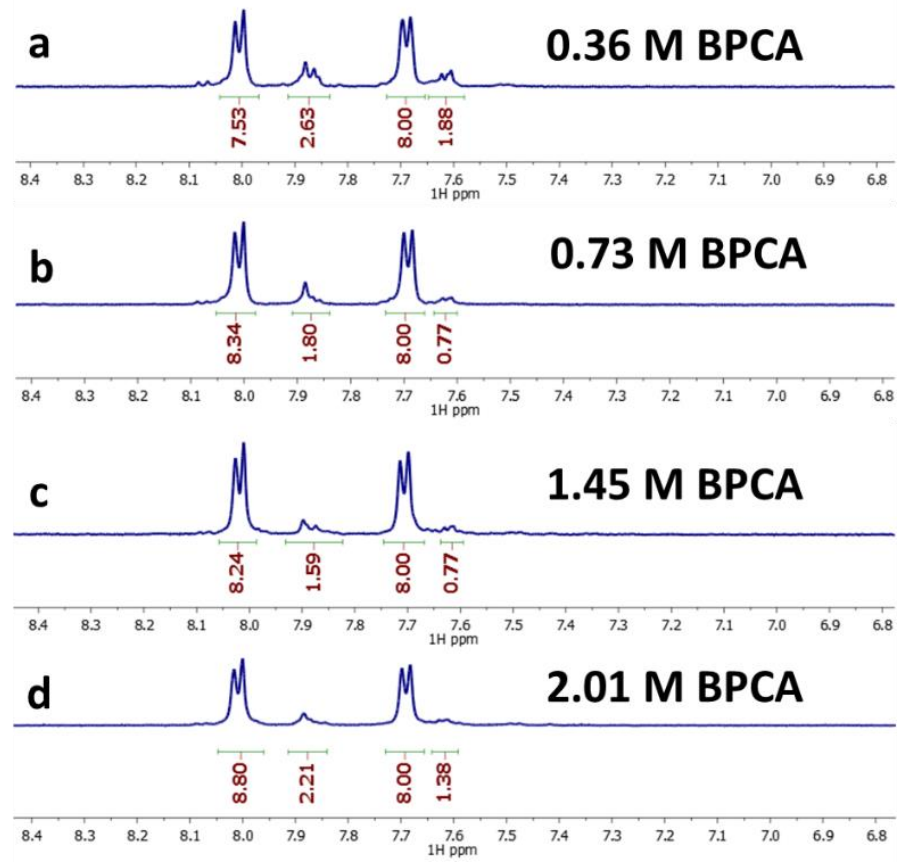

Figure S5. ${ }^{1} \mathrm{H}$ NMR spectra of NU-1000 synthesized using varying BPCA concentrations. The integrations are normalized to the peaks around $7.7 \mathrm{ppm}$. The peaks around 7.7 and $8.0 \mathrm{ppm}$ correspond to the linker and the peaks around 7.6 and 7.87 correspond to BPCA.

\section{X-Ray Diffraction}

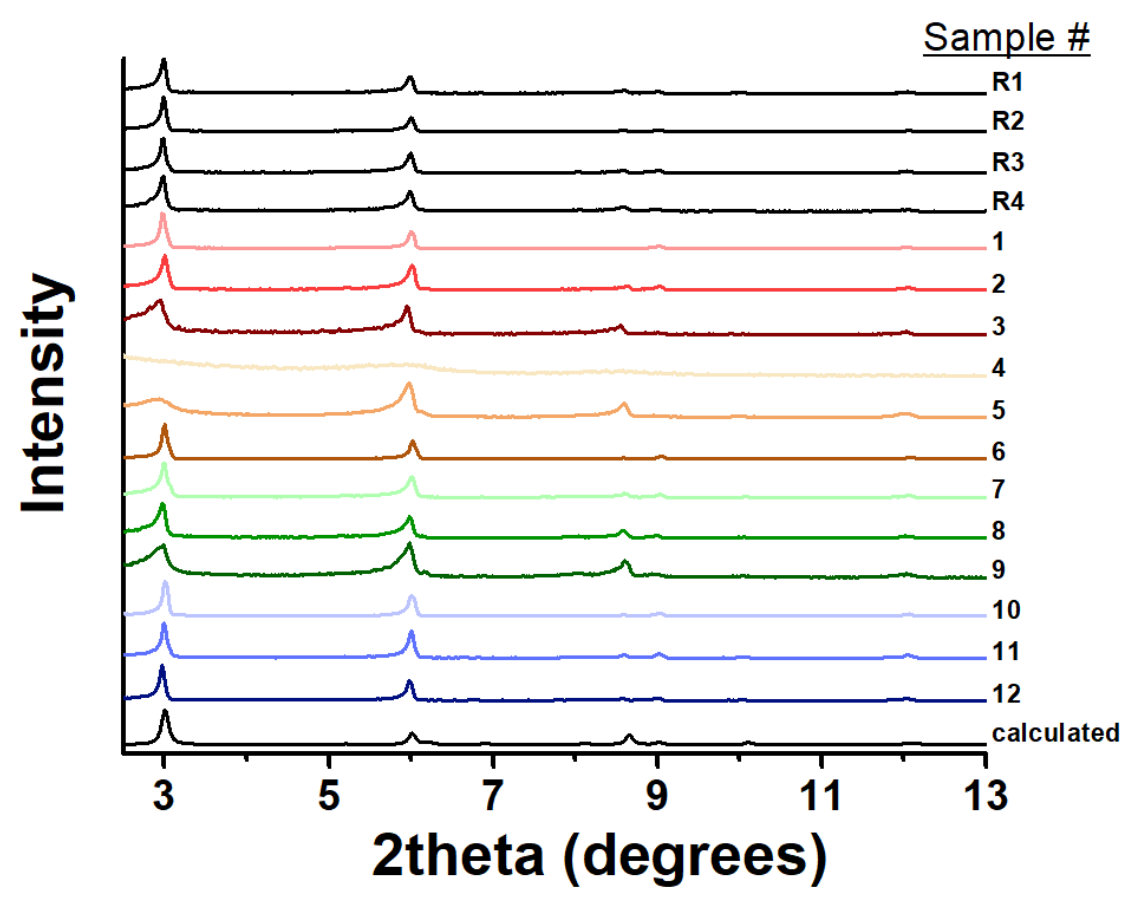

Figure S6. Low angle powder X-ray diffraction patterns of every sample showing the two main peaks of NU-1000 at $3^{\circ} 2$ theta and $6^{\circ} 2$ theta. 


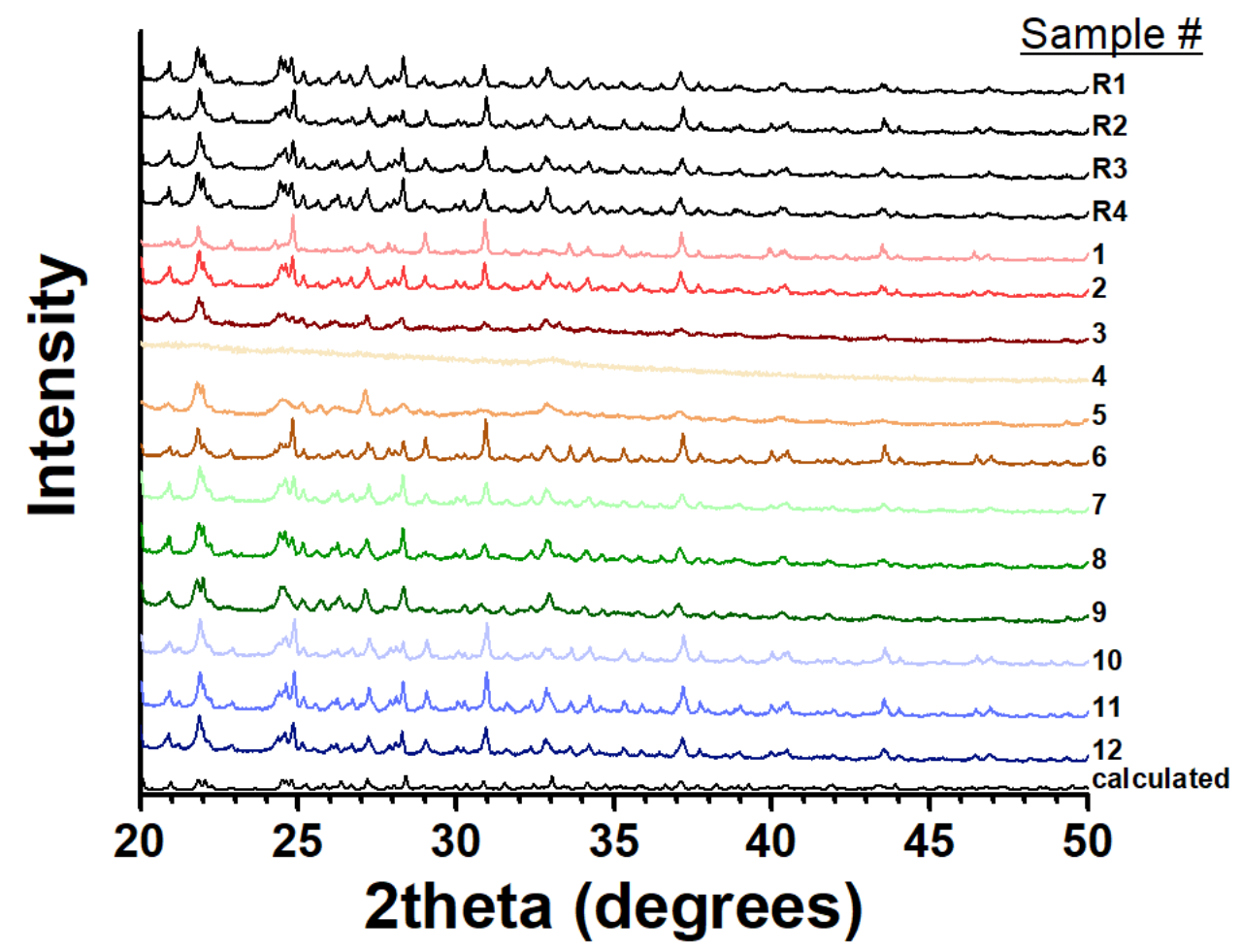

Figure S7. High angle powder X-ray diffraction patterns of every sample in the manuscript.

\section{Dicobalt Complex Immobilization}

Table S2. Experimental conditions and resulting surface areas, particle sizes, and the loading of the dicobalt complex by STEM-EDS and ICP. *Serves to highlight the experimental parameter modified as compared to sample REF. ${ }^{\ddagger}$ No value given because individual particles could not be discerned from TEM images.

\begin{tabular}{|c|c|c|c|c|c|c|c|c|}
\hline $\begin{array}{c}\text { Sample } \\
\text { Number }\end{array}$ & Zr Source & $\begin{array}{c}{[\text { linker }]} \\
(\mathrm{mM})\end{array}$ & $\begin{array}{c}{[\mathrm{BPCA}]} \\
(\mathrm{M})\end{array}$ & $\begin{array}{c}{[\mathrm{NaOH}] /} \\
{[\text { linker }]}\end{array}$ & $\begin{array}{c}\text { Surface } \\
\text { Area } \\
\left(\mathrm{m}^{2} / \mathrm{g}\right)\end{array}$ & $\begin{array}{c}\text { Particle } \\
\text { size } \\
(\mu \mathrm{m})\end{array}$ & \multicolumn{2}{|c|}{$\mathrm{Co}_{2} /$ node by } \\
\cline { 7 - 10 } & & & & $\mathrm{EDS}$ & $\mathrm{ICP}$ \\
\hline $\mathbf{R E F}$ & $\mathrm{ZrOCl}_{2} \bullet 8 \mathrm{H}_{2} \mathrm{O}$ & 6.7 & 1.45 & 0.5 & 2174 & $2.9 \pm 0.8$ & 1.5 & 1.5 \\
\hline $\mathbf{3}$ & $\mathrm{ZrOCl}_{2} \bullet 8 \mathrm{H}_{2} \mathrm{O}$ & $13.3^{*}$ & 1.45 & 0.5 & 2252 & $0.77 \pm 0.07$ & 1.7 & 1.7 \\
\hline $\mathbf{4}$ & $\mathrm{ZrOCl}_{2} \bullet 8 \mathrm{H}_{2} \mathrm{O}$ & 6.7 & $0.36^{*}$ & 0.5 & 1095 & $-{ }^{\ddagger}$ & 2.2 & 1.3 \\
\hline $\mathbf{5}$ & $\mathrm{ZrOCl}_{2} \bullet 8 \mathrm{H}_{2} \mathrm{O}$ & 6.7 & $0.73^{*}$ & 0.5 & 2285 & $0.30 \pm 0.03$ & 1.6 & 0.9 \\
\hline $\mathbf{9}$ & $\mathrm{ZrOCl}_{2} \bullet 8 \mathrm{H}_{2} \mathrm{O}$ & 6.7 & 1.45 & $4^{*}$ & 1676 & $0.42 \pm 0.03$ & 1.9 & 1.8 \\
\hline $\mathbf{1 0}$ & $\mathrm{ZrCl}_{4}{ }^{*}$ & 6.7 & 1.45 & 0.5 & 2052 & $7.9 \pm 1.5$ & 1.0 & 1.0 \\
\hline
\end{tabular}

\section{References}

S1. Desai, S. P.; Malonzo, C. D.; Webber, T.; Duan, J.; Thompson, A. B.; Tereniak, S. J.; DeStefano, M. R.; Buru, C. T.; Li, Z.; Penn, R. L.; Farha, O. K.; Hupp, J. T.; Stein, A.; Lu, C. C., Assembly of dicobalt and cobalt-aluminum oxide clusters on metal-organic framework and nanocast silica supports. Faraday Discuss 2017, 201 (0), 287-302. 
S2. Desai, S. P.; Ye, J.; Zheng, J.; Ferrandon, M. S.; Webber, T. E.; Platero-Prats, A. E.; Duan, J.; Garcia-Holley, P.; Camaioni, D. M.; Chapman, K. W.; Delferro, M.; Farha, O. K.; Fulton, J. L.; Gagliardi, L.; Lercher, J. A.; Penn, R. L.; Stein, A.; Lu, C. C., Well-Defined Rhodium-Gallium Catalytic Sites in a MetalOrganic Framework: Promoter-Controlled Selectivity in Alkyne Semihydrogenation to E-Alkenes. J. Am. Chem. Soc. 2018, 140 (45), 15309-15318.

S3. Thompson, A. B.; Pahls, D. R.; Bernales, V.; Gallington, L. C.; Malonzo, C. D.; Webber, T.; Tereniak, S. J.; Wang, T. C.; Desai, S. P.; Li, Z.; Kim, I. S.; Gagliardi, L.; Penn, R. L.; Chapman, K. W.; Stein, A.; Farha, O. K.; Hupp, J. T.; Martinson, A. B. F.; Lu, C. C., Installing Heterobimetallic Cobalt-Aluminum Single Sites on a Metal Organic Framework Support. Chem. Mater. 2016, 28 (18), 6753-6762.

S4. Webber, T. E.; Liu, W.-G.; Desai, S. P.; Lu, C. C.; Truhlar, D. G.; Penn, R. L., Role of a Modulator in the Synthesis of Phase-Pure NU-1000. ACS Appl. Mater. Interfaces 2017, 9 (45), 39342-39346. 